\title{
A comparison of North American and West European oyster embryo-larval toxicity tests on North Sea sediments
}

\author{
Ray Butler ${ }^{1}$, Peter M. Chapman ${ }^{2}$, Peter van den Hurk ${ }^{3}$, Brian Roddie ${ }^{1, *}$, \\ John E. Thain ${ }^{4}$
}

\footnotetext{
${ }^{1}$ Water Research Centre, Henley Road, Medmenham, PO Box 16 Marlow, Buckinghamshire SL7 2HD, United Kingdom

${ }^{2}$ EVS Consultants, 195 Pemberton Avenue, North Vancouver, British Columbia, Canada V7P 2R4

${ }^{3}$ Bureau Waardenburg bv, PO Box 365, 4100 AJ Culemborg. The Netherlands

${ }^{4}$ Ministry of Agriculture, Fisheries and Food, Fisheries Laboratory, Remembrance Avenue, Burnham-on-Crouch,
} Essex CM0 8HA, United Kingdom

\begin{abstract}
During the Bremerhaven Workshop, Pacific oyster embryos Crassostrea gigas were exposed both directly to sediment and to elutriates of sediment from 2 transects through contamination gradients in the North Sea. One transect consisted of 7 stations down-current from an abandoned drilling site off the Dutch coast. The other transect comprised 9 stations in the German Bight positioned in a northwesterly direction from the Elbe-Weser plume out to the Dogger Bank. The toxicity tests, conducted by 4 research laboratories, were carried out either immediately following sediment sampling on board a research vessel, or after periods of up to $4 \mathrm{wk}$ after sediment collection at mainland laboratories in the UK, Canada and The Netherlands. Oyster embryo-larval sediment elutriate tests showed highest levels of toxicity at the most contaminated sites on the German Bight transect, but data were not consistent on the drilling site transect. The optimal method of sediment elutriation should be determined by further studies. Oyster embryos exposed directly to sediment over a $48 \mathrm{~h}$ period identified the most toxic and contaminated sites from both transects and gave comparable results to infaunal amphipod acute toxicity tests. This study has demonstrated that oyster embryo-larval tests can easily be carried out on board a sea-going research vessel, although there is no absolute requirement to do so when sediment samples can be returned to mainland laboratories within a few days after collection.
\end{abstract}

\section{INTRODUCTION}

The sea-going Bremerhaven Workshop had the principal objective of identifying relevant techniques which could be incorporated into monitoring programmes and to evaluate new biological indices of stress.

A sediment bioassay group conducted a suite of toxicity tests on samples collected along transects in 2 areas of expected anthropogenic contamination in the North Sea. One transect consisted of 7 stations downcurrent from an abandoned drilling site off the Dutch

\footnotetext{
- Present address: Environment + Resource Technology Ltd, Waterside House, 46 The Shore, Leith, Edinburgh. EH6 6QV, United Kingdom
}

coast. The other transect comprised 9 stations in the German Bight positioned in a northwesterly direction from the Elbe-Weser plume out to the Dogger Bank Station positions and designations are given by Stebbing \& Dethlefsen (1992). This paper describes and compares sediment tests using oyster embryos.

The use of oyster embryos as a sensitive measure of water quality and toxicity was initially proposed by Woelke (1972). Subsequently, Chapman \& Becker (1986) modified the test in order to determine the toxicity of sediments by direct exposure of embryos to sediment in seawater. Butler (1990a) and Thain (pers. comm.) have demonstrated sediment toxicity by exposing embryos to sediment elutriates. This paper compares 4 methods of sediment toxicity characterisation using oyster embryos. These methods differed in re- 
spect of exposure method and exposure duration; 2 methods exposed embryos for $24 \mathrm{~h}$ to elutriates prepared in different ways, and 2 methods exposed embryos to whole settled sediments for 24 or $48 \mathrm{~h}$. The end-point of all tests was the ability of the oyster embryo to develop normally to the D-shaped larval stage within 24 or 48 h lat which time the paired hinged shells can be seen). It is during this period of intense cellular development that critical physiological and biochemical processes take place. Disruption of these processes can cause poor growth and development, abnormality and mortality. Without a protective shell the embryonic cells are extremely vulnerable and sensitive to the quality of test media.

Failure of oyster embryos to reach the D-shaped larval stage due to contaminant-induced delayed metamorphosis, abnormality or mortality has important consequences for subsequent recruitment. Pacific oysters, aithough not indigenous to the North Sea, are farmed extensively in shallow coastal and estuarine waters bordering the North Sea. Because of this economic importance, as well as the fact that they are sensitive indicators of water quality (Thain 1991), Pacific oysters are appropriate for use in North Sea pollution monitoring

The objectives of this paper are to: (1) report and compare the results of the oyster embryo-larval sediment toxicity tests performed at 4 laboratories, and (2) make specific recommendations concerning the design and use of the tests.

\section{METHODS}

Triplicate samples of sediment from 7 stations on the drilling site transect were collected on March 13 to 15 , 1990. The stations were located in the residual current direction of $066^{\circ}$ from the point source (location $F$, $54^{\circ} 06^{\prime} 15.0^{\prime \prime} \mathrm{N}, 04^{\circ} 45^{\prime} 33.0^{\prime \prime} \mathrm{E}$ ) (see Stebbing \& Dethlefsen 1992). The stations were designated $A$ to $G$ and collected at $0,125,250,500,1000,2000$ and $5000 \mathrm{~m}$ from the drilling site respectively. A Reineck box corer $\left(0.13 \mathrm{~m}^{2}\right)$ was used to collect sediments from Stns $A, D$, $E, F \& G$ whilst Stns $B$ \& $C$ were sampled using a Van Veen grab $\left(0.1 \mathrm{~m}^{2}\right)$ due to adverse weather conditions. For each station duplicate samples of each replicate were collected for oyster larval bioassays by placing approximately $5 \mathrm{l}$ of sediment from the $20 \mathrm{~cm}$ surface layers of each sample into clean, labelled polyethylene bags. The samples were maintained at $6^{\circ} \mathrm{C}$. The remainder of the sediment was frozen for subsequent chemical analysis (Cofino et al. 1992). The samples were removed from the bags on March 17, and homogenised in stainless steel bowls pre-cleaned with acetone and seawater as described by Chapman (1988).
Each sample was then subdivided into 11 aliquots for each of the participating laboratories. The subsamples were placed into double polyethylene bags from which air had been excluded and were delivered in coolboxes packed with blue ice.

Sediment samples from 9 stations on the German Bight transect were collected using Van Veen grabs between March 27 and 29, 1990. The innermost stations (Stns 1 to 3 ) were sited near to the Elbe and Weser estuaries, whilst the outermost site (Stn 9) was on the Dogger Bank. Two research vessels collected the samples: 4 replicates of the top $4 \mathrm{~cm}$ of sediment were collected from the innermost stations (1 to 6) using a $0.1 \mathrm{~m}^{2}$ Van Veen grab and 3 replicates of the top $10 \mathrm{~cm}$ of sediment were collected using a $0.2 \mathrm{~m}^{2}$ Van Veen grab from the 3 outermost stations ( 6 to 9). Stn 6 was sampled by both vessels. Samples were stored and divided similarly to the drilling site sediments with homogenisation and splitting being carried out on March 29. Sub-samples for chemical analysis were taken from the homogenised sediment.

Pacific oyster embryos Crassostrea gigas were exposed to sediment directly and to elutriates, at a range of temperatures over different exposure periods and at different densities.

EVS Consultants, in Canada, conducted tests according to the procedures described by ASTM (1986) and Chapman \& Becker (1986) between April 10 and 12,1990 . Test vessels were prepared by adding $20 \mathrm{~g}$ of sediment to $1 \mathrm{l}$ polyethylene beakers, adding $1 \mathrm{l}$ of clean seawater, shaking the sediment for $10 \mathrm{~s}$ and then leaving the sediment to settle for $1 \mathrm{~h}$ prior to introducing embryos. Two laboratory replicates were tested for each drilling site sample and one test vessel was used for each German Bight sample. Gametes from ripe adult oysters were obtained by controlled spawning using thermal and biological stimulation. The eggs from a single female were washed through a $250 \mu \mathrm{m}$ Nitex screen to remove gonadal tissue debris and were fertilised with 20 to $50 \mathrm{ml}$ of sperm solution from a single male in a $2 \mathrm{l}$ beaker. Within $2 \mathrm{~h}$ of fertilisation, approximately 23000 embryos were added to each test vessel and incubated at $20^{\circ} \mathrm{C}$ for $48 \mathrm{~h}$ under a $14: 10 \mathrm{~h}$ light : dark photoperiod without aeration. After $48 \mathrm{~h}$, as much of the overlying water as possible was syphoned from each test vessel without disturbing the sediment and representative samples were preserved with buffered formalin. Normal and abnormal larvae were enumerated using a Sedgewick-Rafter cell.

Testing in The Netherlands at the Tidal Waters Division (TWD) followed the Canadian approach of Chapman \& Morgan (1983), in that oyster embryos were exposed directly to test sediments as described above. Tests followed the English procedure of Thain \& Watts (1984) which obtained gametes by stripping as 
opposed to spawning. Fertilised eggs from 3 females were pooled giving a density of approximately 53000 embryos $1^{-1}$. Oyster embryos were introduced to drilling site sediments on March 20 and German Bight sediments on April 4, 1990. Gamete stripping does not appear to affect the quality or viability of the embryos (Allen et al. 1986). Embryos were exposed to the test sediments for 24 h at $24{ }^{\circ} \mathrm{C}$ under ambient light after which $80 \%$ of the overlying water was syphoned off through a $30 \mu \mathrm{m}$ filter. The remaining (bottom) $20 \%$ was discarded. Surviving larvae were washed off the filter, preserved with buffered formalin and counted using an electronic particle counter (Coulter Counter).

Testing of oyster larvae in the UK at the WRC laboratory differed from the above methods primarily in the sediment exposure route and followed the methods described by Butler (1990b). Elutriates of test sediments were prepared by mixing $0.25 \mathrm{l}$ of sediment with $0.25 \mathrm{l}$ of reference seawater in $0.5 \mathrm{l}$ polyethylene containers followed by mechanical rolling for $16 \mathrm{~h}$. The sediments were allowed to settle for $1 \mathrm{~h}$, and the supernatants were decanted and then filtered through $0.45 \mu \mathrm{m}$ membrane filters. Each of these aqueous extracts was diluted to 1,10 and $100 \%$ extract in reference seawater for all sites whilst $30 \%$ and $50 \%$ concentrations were included for the drilling site and German Bight stations respectively. Triplicate $30 \mathrm{ml}$ test vessels were inoculated with $2 \mathrm{~h}$ old embryos obtained by the spawning technique described earlier. Gametes were carefully examined before fertilisation to ensure egg maturity and sperm motility were acceptable. Five pairings of individual females and males were prepared and after 90 min the embryos in best condition were selected for testing. An oyster embryo density of $20000 \mathrm{l}^{-1}$ was used in each test vessel and test vessels were inoculated on March 19, 1990, for drilling site sediments and April 2, 1990, for German Bight sediments. After an exposure period of $24 \mathrm{~h}$ at $25^{\circ} \mathrm{C}$ in the dark, the tests were terminated by adding $0.5 \mathrm{ml}$ of $20 \%$ buffered formalin to each test vessel. Aliquots of $5 \mathrm{ml}$ were removed and counted using settling tubes and an inverted microscope.

Sediments from the German Bight transect sampled from a third research vessel were tested by the MAFF laboratory as aqueous extracts using the method described by Thain (1992). This procedure was similar to that con- ducted at WRC although extracts were prepared immediately, on board the research vessel, by mixing $200 \mathrm{ml}$ of sediment with $600 \mathrm{ml}$ seawater, then shaking for $3 \mathrm{~h}$ followed by filtration. Five $30 \mathrm{ml}$ aliquots of each extract, in $50 \mathrm{ml}$ stoppered polystyrene containers, were jnoculated with embryos derived from stripped gametes of 2 males and 3 females. Stns 1, 2 \& 3 were expected to be the most contaminated due to the location close to the mouths of the Elbe and Weser. A $33 \%$ dilution of extracts from these sites was also tested. Oyster embryos were exposed to the extracts at $24^{\circ} \mathrm{C}$ for $24 \mathrm{~h}$ at a density of approximately 50000 embryos $\mathrm{l}^{-1}$. The test was terminated by the addition of $0.5 \mathrm{ml}$ of $20 \%$ buffered formalin to each test vessel and the numbers of normal larvae in $2 \mathrm{ml}$ aliquots from each vessel were counted using a Sedgewick-Rafter cell.

\section{RESULTS AND DISCUSSION}

The results of the Pacific oyster embryo-larval toxicity tests are shown in Tables $1 \& 2$ and Figs. $1 \& 2$. The data are expressed as mean numbers of normal Dshaped larvae from pooled field and laboratory replicates for each station with $95 \%$ confidence intervals.

Numbers of D-larvae shown for the WRC tests are from 100 and $10 \%$ concentrations of the aqueous extracts for drilling site (Table 1) and German Bight (Table 2) stations, respectively, since these concentrations showed the clearest differences between stations. All German Bight station replicates at $100 \%$ extract resulted in complete failure of normal larval develop-

Table 1. Crassostrea gigas. Mean number of oyster embryos developing to normal D-shaped larvae after exposure to elutriates (e) and directly (d) to sediments from the drilling site transect in the North Sea. Numbers in brackets are $95 \%$ confidence intervals. Controls were cultures of embryos in clean seawater. WRC results were for a $100 \%$ concentration of the aqueous extracts. "Significantly different ( $p>0.05)$ from controls

\begin{tabular}{|c|c|c|c|c|}
\hline \multirow[t]{2}{*}{ Stn } & \multirow{2}{*}{$\begin{array}{c}\text { Distance from } \\
\text { centre }(\mathrm{m})\end{array}$} & \multicolumn{3}{|c|}{ Laboratory } \\
\hline & & $\begin{array}{c}\text { WRC } \\
(e) \\
\text { (per } 5 \mathrm{ml})\end{array}$ & $\begin{array}{c}\text { TWD } \\
\text { (d) } \\
\text { (per } 2 \mathrm{ml})\end{array}$ & $\begin{array}{c}\text { EVS } \\
\text { (d) } \\
\text { (per } 5 \mathrm{ml})\end{array}$ \\
\hline $\mathrm{G}$ & 5000 & $0 \quad(0.0)^{\circ}$ & $8 \quad(3.2)$ & $56(17.0)^{\circ}$ \\
\hline $\mathrm{F}$ & 2000 & $20(42.4)^{\circ}$ & $9 \quad(2.0)$ & $70(26.2)^{\circ}$ \\
\hline $\mathrm{E}$ & 1000 & $35(23.8)^{\circ}$ & $7 \quad(3.0)$ & $70(19.0)^{\circ}$ \\
\hline $\mathrm{D}$ & 500 & $127(17.4)$ & $24 \quad(9.4)$ & $77(27.0)^{\circ}$ \\
\hline $\mathrm{C}$ & 250 & $143(12.3\}$ & $22(6.4)$ & $42(10.8)^{\circ}$ \\
\hline $\mathrm{B}$ & 125 & 116 (15.5) & $30 \quad(4.7)$ & $78(17.0)^{\circ}$ \\
\hline A & 0 & $112(18.6)$ & $26 \quad(3.4)$ & $31(14.8)^{\circ}$ \\
\hline Control & & $124(11.5)$ & $15(10.2)$ & $132(14.8)$ \\
\hline $\begin{array}{l}\text { No. of days between } \\
\text { sediment collection } \\
\text { and test initiation }\end{array}$ & & 6 & 8 & 28 \\
\hline
\end{tabular}


Table 2. Crassostrea gigas. Mean number of oyster embryos developing to normal D-shaped oyster larvae after exposure to elutriates (e) and directly (d) to sediments from the German Bight transect in the North Sea. Numbers in brackets are $95 \%$ confidence intervals. Controls were cultures of embryos in clean seawater. WRC results were for a $10 \%$ concentration of the aqueous extracts. 'Significantly different $(p>0.05)$ from controls. - Not tested

\begin{tabular}{|c|c|c|c|c|}
\hline \multirow[t]{2}{*}{ Stn } & \multicolumn{4}{|c|}{ Laboratory } \\
\hline & $\begin{array}{c}\text { WRC } \\
(\mathrm{e}) \\
\text { (per } 5 \mathrm{ml} \text { ) }\end{array}$ & $\begin{array}{c}\text { MAFF } \\
(\mathrm{e}) \\
(\text { per } 2 \mathrm{ml})\end{array}$ & $\begin{array}{c}\text { TWD } \\
\text { (d) } \\
\text { (per } 2 \text { ml) }\end{array}$ & $\begin{array}{c}\text { EVS } \\
\text { (d) } \\
\text { (per } 5 \mathrm{ml})\end{array}$ \\
\hline 1 & $53(52.4)^{\circ}$ & $0 \quad(0.0)^{\circ}$ & $39(12.9)$ & $10(6.5)^{\circ}$ \\
\hline 2 & $84(24.2)^{*}$ & $10(9.7)^{\bullet}$ & $64\{11.9\}$ & $44(21.9)^{\circ}$ \\
\hline 3 & $87(47.6)$ & $57 \quad(9.9)$ & $93(11.1)$ & $16(20.4)^{\circ}$ \\
\hline 4 & $120 \quad(5.7)$ & $71(10.3)$ & $83(19.3)$ & $26(15.6)^{\circ}$ \\
\hline 5 & $122 \quad(3.9)$ & $73 \quad(7.2)$ & $79 \quad(9.9)$ & $49(60.3)^{\circ}$ \\
\hline $6 a$ & $121 \quad(8.0)$ & $66 \quad(8.6)$ & $75(25.4)$ & $67(66.6)^{\circ}$ \\
\hline $6 b$ & 119 (7.3) & - & $62(11.0)$ & $49(77.7)^{\circ}$ \\
\hline 7 & $118 \quad(8.5)$ & $72 \quad(7.0)$ & $45(15.0)$ & $54(60.3)^{\circ}$ \\
\hline 8 & $124 \quad(7.0)$ & $64 \quad(8.4)$ & $41(16.5)$ & $71(14.9)^{\circ}$ \\
\hline 9 & $110(13.0)$ & $66 \quad(6.1)$ & $32\{21.0\}$ & $85(15.1)^{\circ}$ \\
\hline Control & $124(11.5)$ & $69 \quad(4.4)$ & $68(47.1)$ & $132(14.8)$ \\
\hline $\begin{array}{l}\text { No. of days between } \\
\text { sediment collection } \\
\text { and test initiation }\end{array}$ & 6 & 0 & 8 & 14 \\
\hline
\end{tabular}

(b) there may have been differences in the degree of sorption/ complexation of contaminants between samples which influenced the effectiveness of different elutriation methods and therefore the quantities of available contaminants present in the elutriates;

(c) uncontrolled variation in sediment sub-sampling depth and volume for chemical and toxicological characterisation may have distorted the observed patterns of toxicity and contamination. This hypothesis might account for some of the observed differences on the German Bight transect between WRC and MAFF results (Table 2).

It is possible that embryos used by WRC in the German Bight study were more sensitive than those used in the drilling site study, although this cannot be established since no reference toxicants were

ment, whereas only 3 stations from the drilling site transect showed significantly reduced $(\mathrm{p}>0.05)$ larval development at the same extract concentration. Embryo development in the $1 \%$ concentration of all sediment extracts tested at WRC was not significantly different from control cultures in clean seawater The $33 \%$ dilution of elutriates used at German Bight Stns 1 to 3 in the MAFF test resulted in no significant reduction in normal embryo development compared to the control and so only the data from the $100 \%$ extract were tabulated here (Table 2). The difference between the 2 WRC studies with $100 \%$ concentrations of extracts may have resulted from a higher overall level of contamination at all German Bight stations compared with drilling site stations. A preliminary comparison of provisional chemical data (Cofino et al. 1992) did not reveal any clear pattern of contamination within or between transects to which the occurrence of $100 \%$ abnormality in the $100 \%$ extracts could be related. Outer German Bight station sediments causing this degree of effect appeared less contaminated than inner drilling site sediments with lower apparent toxicity; conversely, however, inner drilling site sediments were not apparently less contaminated than sediments up to $5000 \mathrm{~m}$ from the site, although the latter produced a more severe effect. There is at present insufficient evidence from which to draw firm conclusions, but the following hypotheses are proposed:

(a) unmeasured contaminants may have contributed to the toxicity; tested. It seems equally probable, however, that the differences observed were attributable to one or more of the factors noted above. Reference toxicants and sediments need to be standardised and included in all studies so that differences in embryo-larval sensitivity can be taken into account for intra-laboratory and inter-laboratory comparisons.

Only the EVS laboratory enumerated the approximate number of embryos inoculated into test vessels and so comparisons of embryo mortality between laboratories was not possible. The MAFF tests did not enumerate abnormal larvae present and the TWD study determined the total number of surviving larvae using a Coulter Counter and therefore could not distinguish between normality and abnormality. The TWD study made the assumption that larvae swimming up from the sediment surface were predominantly normal, although EVS tests showed that as many as $57 \%$ of larvae sampled from above the sediment surface were abnormal.

Cofino et al. (1992) have measured a clear gradient of hydrocarbon and heavy metal anthropogenic contaminants in the German Bight transect sediments proceeding from shore to Dogger Bank. The gradient of contamination in the drilling site sediments was less clearly defined. Oyster embryo-larval toxicity tests showed a similar trend in relation to contamination on the German Bight transect for all tests except TWD which demonstrated an inverse relationship (Table 2). Although there was no clear trend of contamination at 


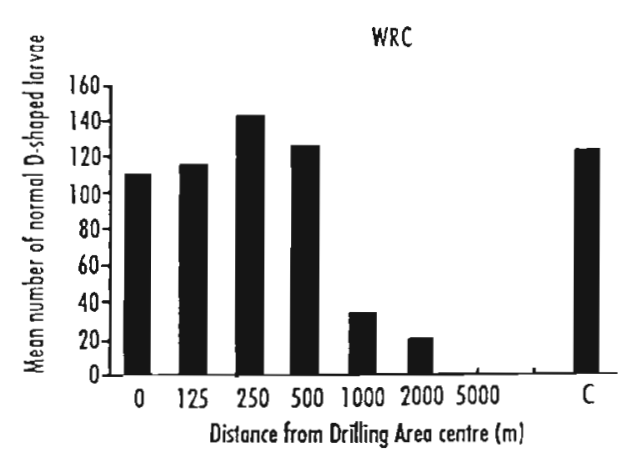

TWD
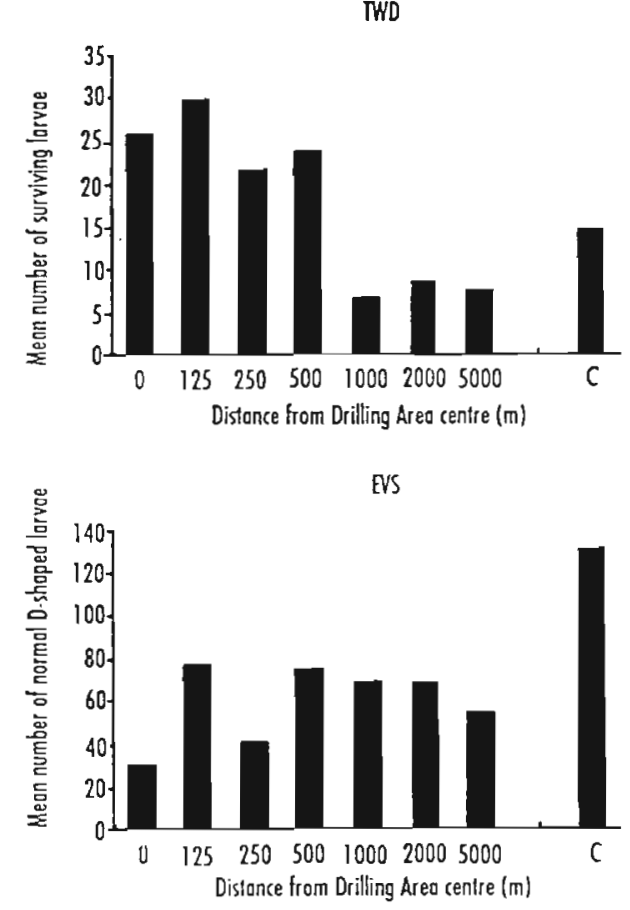

Fig. 1. Crassostrea gigas. Mean number of normal D-shaped oyster larvae (or surviving larvae) after 24 or $48 \mathrm{~h}$ exposure to elutriates (WRC laboratory) or directly (TWD and EVS laboratories) to sediments from the Drilling Area transect in the North Sea

the drilling site transect indicated by the analytical chemistry, toxicity was demonstrated by all 3 laboratories (Table 1).

Testing carried out on elutriates by WRC and MAFF at Stns $1 \& 2$ demonstrated that there were significantly ( $p>0.05$ ) reduced numbers of enbryos successfully reaching normal D-shaped larvae compared to control cultures (Table 2). Stn 3 in both studies also gave rise to low levels of normal development, but high variance meant that significant differences could not be detected. Test results for elutriates of sediment from the other stations ( 4 to 9 ) indicated no significant difference $(p>0.05)$ compared with clean seawater controls. Embryos exposed directly to the sediments
(TWD and EVS) also showed reduced normal development at Stn 1. Low normal embryo-larval development was observed by TWD at Stns 7, 8 \& 9; however, high variability in control and test sediment vessels resulted in no statistically significant differences at these stations compared with the control.

The pattern of response of embryos exposed to the drilling site sediments was not consistent. Tests carried out by WRC and TWD appear to indicate increasing toxicity with increased distance from the centre of the drilling area. The test conducted by EVS suggests that the most toxic stations were $A$ and $C$ at 0 and $250 \mathrm{~m}$ from the centre respectively. The TWD study may be indicating false positive toxicity, since the 4 samples containing the lowest number of larvae were counted on one day and the remaining preserved samples were counted on the following day. Overall, for both transects, the EVS results best match information on the sediment contamination and the results of other toxicity tests (Chapman et al. 1992) This may be a result of the longer exposure period ( $48 \mathrm{~h}$ as opposed to $24 \mathrm{~h}$ used by WRC and TWD). The infaunal amphipod Corophium volutator was exposed to the same drilling site sediments over a $10 \mathrm{~d}$ period. After $3 \mathrm{~d} C$. volutator exposed to sediment from the innermost sites came to the sediment surface and appeared narcotised (van den Hurk et al. 1992). The elutriation process used in the WRC oyster embryo test involved only a $16 \mathrm{~h} \mathrm{mix-}$ ing period and it was therefore possible that contaminants had not been fully eluted. The sediment chemistry for the outermost stations does not explain or coincide with the toxicity observed in the WRC test. Retrospectively it would have been useful to have conducted chemical analyses on the sediment elutriates.

The initial embryo densities used by each laboratory varied from 20 to $50 \mathrm{ml}^{-1}$; however, by assessing different volumes of test solution, each laboratory aimed to count approximately 100 larvae at the end of the tests. Low numbers of larvae were recovered from tests exposing embryos directly to the sediments which may indicate an inherent weakness in the test by failing to collect larvae from the sediment water interface. The TWD tests removed only $80 \%$ of the overlying water from the sediment and it was likely in this case that a substantial proportion of larvae were not sampled.

\section{CONCLUSIONS}

(1) Oyster embryos exposed directly to sediment over a $48 \mathrm{~h}$ period identified the most contaminated and toxic stations from both transects.

(2) Oyster embryo-larval tests on sediment elutriates showed the highest levels of toxicity at the most contaminated stations on the German Bight transect. 

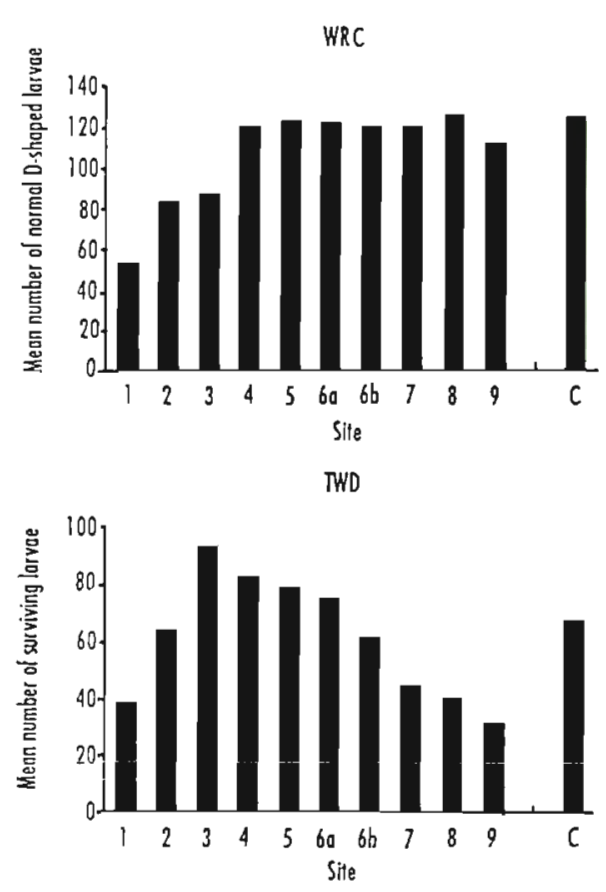
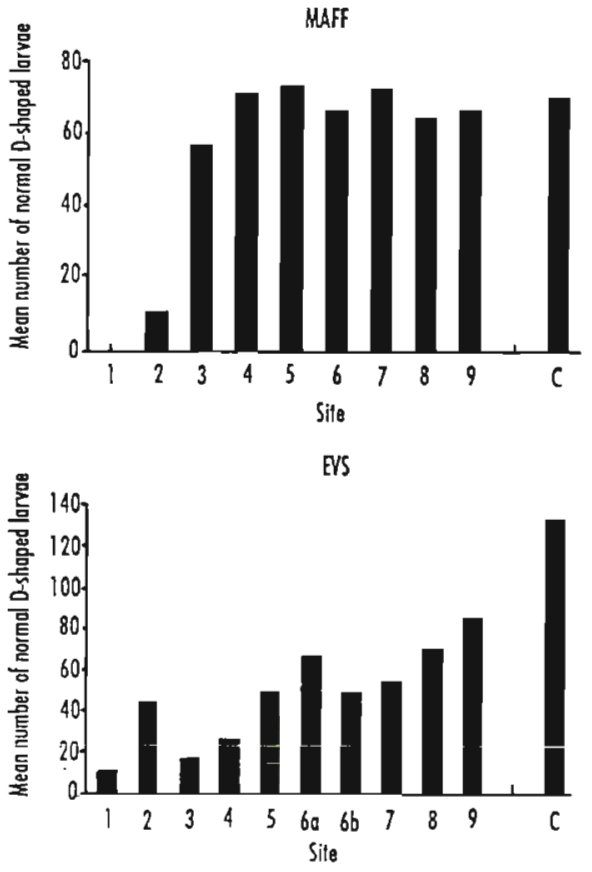

Fig. 2. Crassostrea gigas. Mean number of normal $D$ shaped oyster larvae (or surviving larvae) after 24 or $48 \mathrm{~h}$ exposure to elutriates (WRC and MAFF laboratories) or directly (TWD and EVS laboratories) to sediments from the German Bight transect of the North Sea
(3) At the drilling site transect the data were not consistent between laboratories. EVS results showed a reduction in toxicity further away from the drilling centre; WRC and TWD showed the opposite trend.

(4) The data suggest that there are differences in test results which resulted from variations in the procedures used.

\section{RECOMMENDATIONS}

(1) Comprehensive studies should be undertaken to establish whether elutriation of sediments provides samples which adequately reflect contamination and toxicity.

(2) Assuming elutriation can provide representative samples, the optimal method of elutriate preparation should be determined by conducting a range of toxicity tests and chemical analysis on a variety of contaminants partitioning between sediments and seawater.

(3) Oyster embryo-larval toxicity test methods on sediments should be standardised. Standardisation would provide guidance on the use of elutriates versus whole sediments, controls (clean and spiked), enumeration techniques, sample holding time and procedures.

(4) Oyster embryo-larval toxicity tests on sediments can easily be carried out on sea-going research vessels with minimal laboratory space and equipment. However, samples tested up to 3 wk after collection showed similar trends in toxicity compared with samples tested immediately following collection.
Acknowledgements. A large number of individuals contributed to the testing and sampling effort. We thank field crews involved in the sampling and the Workshop organisers and support staff, in particular Tony Stebbing and Martin Carr. UK field studies formed part of a research programme funded by the National Rivers Authority whose permission to participate and publish is gratefully acknowledged. Partial funding for this work was provided by EVS Consultants, IMO and IOC. External peer review was provided by Drs W. Adams (ABC Laboratories) and R. Swartz (U.S. EPA).

\section{LITERATURE CITED}

Allen, S. K. Jr, Downing, S. L., Chew, K. K. (1986). Hatchery manual for producing triploid oysters. Washington Sea Grant Program, University of Washington Press, Seattle

ASTM (1986). Standard practice for conducting static acute toxicity tests with larvae of four species of bivalve molluscs. In: Annual Book of ASTM Standards, Water and Environmental Technology, Vol. 11.04. American Society for Testing and Materials, Philadelphia, p. 368-384

Butler, R. (1990a). The use of the oyster embryo-larval toxicity test to determine the biological quality of aqueous extracts of Mersey sediments and water samples before and after an oil spill. WRC Report No. PRS 2421-M

Butler, R. (1990b). Determination of the 24 hour EC50 of test substances to Crassostrea gigas under non-axenic conditions. Water Research Centre Standard Operating Procedure No. EP 504, 25 pp.

Chapman, P. M. (1988). Marine sediment toxicity tests. In: Lichtenberg, J. J., Winter, F. A., Weber, C. I., Fradkin, L (eds.) Chemical and biological characterisation of sludges, sediments, dredge spoils and drilling muds ASTM STP 976. American Society for Testing and Materials, Philadelphia, p. $391-402$ 
Chapman, P. M., Becker, S. (1986). Recommended protocols for conducting laboratory bioassays of Puget Sound sediments. U.S. Environmental Protection Agency, Puget Sound Estuary Program, Seattle

Chapman, P. M., Morgan, J. D. (1983). Sediment bioassays with oyster larvae. Bull. environ. Contam. Toxicol. 34: 438-444

Chapman, P. M., Swartz, R. C., Roddie, B., Phelps, H. L., van den Hurk, P., Butler, R. (1992). An international comparison of sediment toxicity tests in the North Sea. Mar. Ecol. Prog. Ser, 91: 253-264

Cofino, W. P., Smedes, F., de Jong, S. A., Abarnou, A., Boon, J. P., Oostingh, I., Davies, I. M., Klungsøyr, J., Wilhelmsen, S., Law, R. J., Whinnett, J. A., Schmidt, D., Wilson, S. (1992). The chemistry programme. Mar. Ecol. Prog. Ser. 91: $47-56$

Stebbing, A. R. D., Dethlefsen, V. (1992). Introduction to the Bremerhaven Workshop on Biological Effects of Contaminants. Mar. Ecol. Prog. Ser. 91: 1-8

Thain, J. E (1991). Biological effects of contaminants: oyster
(Crassostrea gigas) embryo bioassay. Techniques in Marine Environmental Sciences, No. 11, February 1991. ICES, Copenhagen

Thain, J (1992). Use of the oyster Crassostrea gigas embryo biossay on water and sediment elutriate samples from the German Bight. Mar. Ecol. Prog. Ser. 91: 211-213

Thain, J. E., Watts, J. L. (1984). The use of a bioassay to measure changes in water quality associated with a bloom of Gyrodinium aureolum (Hulbert). ICES Special Meeting on the causes, dynamics and effects of exceptional marine blooms and related events, Copenhagen, 4-5 October 1984. Paper D:3

van den Hurk, P., Chapman, P. M., Roddie, B., Swartz, R. C. (1992). A comparison of North American and West European infaunal amphipod species in a toxicity test on North Sea sediments. Mar. Ecol. Prog. Ser. 91: 237-243

Woelke, C. E. (1972). Development of a receiving water quality bioassay criterion based on the 48-hour Pacific oyster (Crassostrea gigas) embryo. Tech. Rep. Dept. Fish. Wash. 9: $1-93$ 